Sofija A. Bilandžija*

Univerzitet u Beogradu

Filološki fakultet

Katedra za germanistiku

\title{
O POJMU I ODREĐENJU KAUZATIVNOG GLAGOLA U SAVREMENOM NORVEŠKOM JEZIKU
}

\author{
Originalni naučni rad \\ UDC 811.113.5'367.625 \\ https://doi.org/10.18485/kkonline.2021.12.12.5
}

\begin{abstract}
U norveškoj, kao ni skandinavističkoj gramatičkoj literaturi, ne postoji konsenzus oko toga šta se može smatrati kauzativnim glagolom. Termini kauzativni glagol i/ili kauzativ se često definišu neujednačeno i preusko $s$ obzirom na to da se javljaju u opoziciji prema terminima rezultativ i faktitiv, iako ih obimna kauzativistička literatura u poslednjih pet decenija sve obuhvata pod pojmom kauzativa. U ovom radu predlažemo supklasifikaciju kauzativnih glagola u savremenom norveškom jeziku na pomoćne i leksičke, a leksičke potom dalje supklasifikujemo na osnovu toga da li iskazuju samo komponentu kauzacije, ili uz nju dodatno specifikuju i uzročni/uzrokovani događaj ili pak sve komponente složene kauzativne makrosituacije. Na osnovu toga izdvajamo jednokomponentne, dvokomponentne i trokomponentne kauzativne glagole, obraćajući posebnu pažnju na obeležja agentivnosti (svesnost, volja, namera i kontrola) u vezi sa licenciranjem specifičnih učesnika na poziciji kauzatora.
\end{abstract}

Ključne reči: kauzativnost, kauzativni glagol, kauzativ, kauzativna situacija, kauzativna konstrukcija, norveški jezik.

\section{Uvod}

Istraživanja kauzativnosti u skandinavskim jezicima nisu obimna, uprkos tome što je ova tema na svetskom nivou predmet mnogobrojnih i višedecenijskih tipoloških, semantičkih i sintaksičkih istraživanja. U svojim istraživanjima semantike kauzativnosti u savremenom norveškom jeziku suočili smo se sa izazovom koji predstavlja manjak određenja toga šta se u norveškom jeziku može smatrati kauzativnom konstrukcijom, odn. kauzativom, a posebno određenja toga šta se, makar tradicionalno, može smatrati kauzativnim glagolom. Uočili smo da se ovi pojmovi u tradicionalnoj gramatičkoj literaturi o norveškom jeziku ređe obrađuju, te da postoji izvestan stepen razuđenosti shvatanja termina kauzativ.

\footnotetext{
* Filološki fakultet u Beogradu, Studentski trg 3, 11000 Beograd, Srbija; e-mail: sofija.bilandzija@fil.bg.ac.rs i sofija.bilandzija@gmail.com
} 
Postojanje bilo kakve, makar bazične, ali ipak sistematične podele bilo bi od neprocenjivog značaja za sva dalja ispitivanja semantike navedenih konstrukcija, iako se u kauzativistici, prevashodno usled raznovrsnosti formalnih sredstava iskazivanja, kako na međujezičkom, tako i na unutarjezičkom planu, veoma često polazi od onomasiološkog pristupa, u kom se polazi od semantički validne definicije kauzativne situacije (up. concept prédéfini u Hamon, Amy \& Anscombre, 2006: 11), a tek se u narednom koraku ispituju formalne jedinice izražavanja. Osim toga, može postojati i problem terminološkog nepodudaranja, jer ono što kauzativistička literatura naziva kauzativnim glagolom, neretko se u gramatikama i priručnicima naziva rezultativom ili faktitivom.

Stoga ovaj rad ima dvojak cilj: on treba ukratko da predstavi šta se u dostupnoj literaturi smatra kauzativnim glagolom, te da na osnovu sopstvene analize iznese predlog moguće klasifikacije kauzativnih glagola u savremenom norveškom jeziku, te na taj način doprinese supklasifikaciji kauzativnih konstrukcija u ovom jeziku.

\section{Osnovna određenja}

U ovom odeljku izložićemo ukratko nekoliko osnovnih određenja, neophodnih za razumevanje rada. U radu se termin kauzativnost koristi kao termin koji označava širu pojmovno-semantičku kategoriju i njeno izražavanje jezičkim sredstvima ${ }^{1}$ (up. Хазагеров, 1998; Stokstad, 1998; Kelstrup, 2001; Rawoens, 2007), pri čemu se kauzacija (čin uzrokovanja) javlja kao jedna od komponenata složene kauzativne makrosituacije. $U$ tradicionalnoj kauzativistici se kauzativnost u jeziku shvata kao odnos, i to odnos dva događaja među kojima postoji nužna determinisanost prema kojoj prvi događaj dovodi do narednog. Reč je, dakle, o jednoj složenoj kauzativnoj situaciji (u daljem tekstu: KS), makrosituaciji koju čine minimalno dva poddogađaja ili mikrosituacije ('subevent') povezana odnosom kauzacije.

Prvi poddogađaj nazivamo uzročnim događajem ( $u$ daljem tekstu: $D_{1}$ ) i on predstavlja predikaciju uzroka, dok se drugi poddogađaj naziva uzrokovanim događajem ili rezultatom ( $u$ daljem tekstu: $D_{2}$ ) do kog je doveo $D_{1}$. KS se u jeziku izražava različitim tipovima kauzativnih konstrukcija (u daljem tekstu: KK), a od načina formalnog izražavanja koje dati jezik ima na raspolaganju zavisi u kojoj meri će ova

\footnotetext{
1 Stroga distinkcija između termina kauzalnost i kauzativnost nužna je kako bi se izbegla tradicionalna objektivistička zamka da kauzativne konstrukcije izražavaju uzročno-posledične odnose u stvarnosti, što dovodi i do toga da se kodiranje nekog kauzativnog događaja pokušava objasniti u nužnoj korelaciji sa spontanošću prirodnog odvijanja događaja, sklonošću ka entropiji i sl. Pitanje stvarnih kauzalnih veza među entitetima nije u ovom smislu relevantno jer jezik predstavlja konceptualizaciju stvarnosti, te radije govorimo o percepciji događaja. Uprkos tome, valja primetiti da u kauzativistici još uvek postoji visok stepen nepoklapanja u određenju ova tri termina (kauzalnost - kauzativnost - kauzacija).
} 
dva poddogađaja biti eksplicirana. U norveškom jeziku načini formalnog izražavanja podrazumevaju veoma širok spektar formalnih jedinica na različitim jezičkim nivoima (za analitičke kauzativne konstrukcije up. Bilandžija 2013, za morfološki kauzativ up. Bilandžija 2016, za neglagolske kauzativne konstrukcije up. Bilandžija 2018).

Termin kauzativni glagol ( $\mathrm{u}$ daljem tekstu: KG) zauzima centralnu poziciju u razmatranju kauzativnih situacija jer se njime iskazuje komponenta kauzacije, pri čemu u kauzativistici još uvek postoji nekonzistentna upotreba ovog termina, te nije uvek potpuno jasno da li autor pod tim podrazumeva glagol koji izražava sveukupnost KS ili samo onaj koji izražava $D_{1}$. Budući da je prototipični model KS zapravo agentivni model uzročnog lanca, tj. prototipična tranzitivna situacija sa minimalno dva odeljena učesnika u kojoj voljni agens deluje svesno i namerno, usmeravajući svoju aktivnost ka pacijensu, čijom se promenom (fizičkog) stanja kompletira kauzativni događaj (Croft, 1991: 155; Croft, 1998: 89; Rawoens, 2007: 88), u mnogim analizama kauzativnosti se analizira ograničen spektar glagolskih leksema, koje se pritom analiziraju kao instance prototipičnih kauzativnih glagola. To su najčešće glagoli fizičke deformacije objekta ili glagoli narušavanja materijalnog jedinstva objekta, sa značenjima 'ubiti', 'uništiti', 'udariti', 'saviti', 'slomiti', 'iseći' ili 'otvoriti' (za reference up. Vázquez Rozas, 2007: 18).

\section{O pojmu kauzativnog glagola u skandinavskoj literaturi}

Norveški izvori, i skandinavski generalno, termine kauzativni glagol (no. kausativt verb) i kauzativ (no. kausativ) koriste retko, a i tada poprilično nejednoznačno i neujednačeno. Ovi termini se u vodećim skandinavskim gramatikama pojavljuju kao:

(a) glagol koji izražava $\mathrm{S}_{1}$ :

Ovo je način na koji se kauzativni glagoli obrađuju u višetomnoj Gramatici švedske akademije (Svenska akademiens grammatik, u daljem tekstu: SAG) (Teleman, Hellberg i Andersson, II: 512-513). Kauzativni glagol je prema ovoj definiciji onaj glagol koji označava da je referent subjekta uzrok aktivnosti ili promene kod drugog referenta, i ovakvi glagoli se pojavljuju sa obaveznim dopunama (na primer, u vidu podređene infinitivske sintagme), a kauzativno značenje se navodi tek kao jedno od mogućih značenja. Toj grupi bi pripadali, na primer, švedski glagoli komma, fă, låta, förmå, vålla, orsaka. Ovakvo shvatanje KG isključuje iz razmatranja sve one glagole koji se u literaturi smatraju sintetičnim kauzativnim glagolima, a u SAG se ti 
glagoli nazivaju rezultativima (šv. resultativa verb) jer njihovo značenje podrazumeva da radnja vodi ka nekom rezultatu (Teleman et al. II: 504-505). Kako će naša supkategorizacija pokazati, u ovoj grupi se zapravo nalaze i neki glagoli koji se mogu posmatrati i kao pomoćni kauzativni glagoli, kao i neki koji se mogu smatrati punoznačnim leksičkim kauzativima, koji pak iskazuju samo semu kauzacije.

U norveškoj gramatičkoj literaturi se konstrukcije sa glagolom f̊ i infinitivskom sintagmom ređe prepoznaju kao kauzativne, već se instance ove upotrebe posmatraju kao jedna od realizacija glagola fă kao punoznačnog leksičkog glagola (Golden, MacDonald i Ryen, 2008: 82). Jedino Norsk referansegrammatikk, obrađujući fenomen podizanja subjekta, navodi da se ova operacija može posmatrati kao kauzativna konstrukcija (Faarlund, Vannebo i Lie, 1997: 1029).

(b) član kombinacije parverb:

Ovde je reč o ograničenom broju neprelaznih glagola koji se uvek pojavljuju u paru sa svojim tranzitivnim parnjakom, koji je od njih izveden. Takvi su, na primer, parovi sitte - sette, falle - felle ili ligge - legge. Kao kauzativni glagoli se tretiraju posebno u starijim gramatikama i udžbenicima sintakse, gde postoji jasna opozicija prema terminu faktitivan² (Vinje 1990: 118). Ovo bi prema Bilandžija (2016: 191192) zapravo bili predstavnici tzv. morfološkog kauzativa u savremenom norveškom jeziku.

(c) deo konstrukcije sa glagolom fă:

Forlund, Vanebu i Li u najobimnijoj norveškoj gramatici do sada (Norsk referansegrammatikk), pod pojmom kauzativ posmatraju i druge konstrukcije sa glagolom fă (up. tačku a), i to one tradicionalno poznate pod nazivom fa-pasiv (Faarlund et al. 1997: 849, 1029). U ovim konstrukcijama ih kao jednu vrstu kauzativa posmatraju i švedski autori, gde se participska sintagma pojavljuje u službi objekatskog predikativa (Teleman et al. IV: 296). U našim dosadašnjim istraživanjima bi ove konstrukcije bile predstavnici specifične vrste kauzacije koju smo nazvali benefaktivnim kauzativom (Bilandžija, 2015).

\footnotetext{
${ }^{2}$ I Kulikov (2001: 886) naglašava da se ovaj termin, posebno u starijim gramatikama, koristio u istom značenju kao danas kauzativ; za njega su ono što se u literaturi dugo prepoznavalo kao faktitiv zapravo denominalni kauzativi, odn. kauzativi sa značenjem 'činiti kakvim'. SAG parverb u švedskom jeziku ne naziva kauzativima, već podvrstom rezultativa (Teleman et al, II: 505).
} 
Uočavamo, dakle, da je pristup kauzativnim glagolima i njihovo određenje u skandinavskim gramatikama manjkav u odnosu na višedecenijska tipološka, sintaksička i semantička proučavanja kauzativnih konstrukcija i njihove semantike.

\section{Tipovi kauzativnih glagola}

Pod kauzativnim glagolom podrazumevamo glagolsku leksemu koja izražava minimalno komponentu kauzacije, a u sprezi sa komponentom kauzacije može označavati i druge komponente KS. To su glagoli koji izražavaju vršenje kakve aktivnosti nad učesnikom s ciljem da se učesnik navede na to da izvrši neku aktivnost ili s ciljem da se izmeni stanje ili položaj učesnika. One glagole koje pored čina kauzacije izražavaju $D_{1}$ Nedjalkov i Siljnicki nazivaju instrumentalnima, a one koji izražavaju $D_{2}$ nazivaju rezultativnima (Недялков \& Сильницкий 1969: 8-9).

Osim toga, u zavisnosti od toga koje komponente leksikalizuje, KG mogu biti jednokomponentni (izražavaju samo semu kauzacije), dvokomponentni (sema kauzacije $+D_{1}$ ILI sema kauzacije $\left.+D_{2}\right)$ i trokomponentni $\left(D_{1}+\right.$ sema kauzacije + $\left.\mathrm{D}_{2}\right)$.

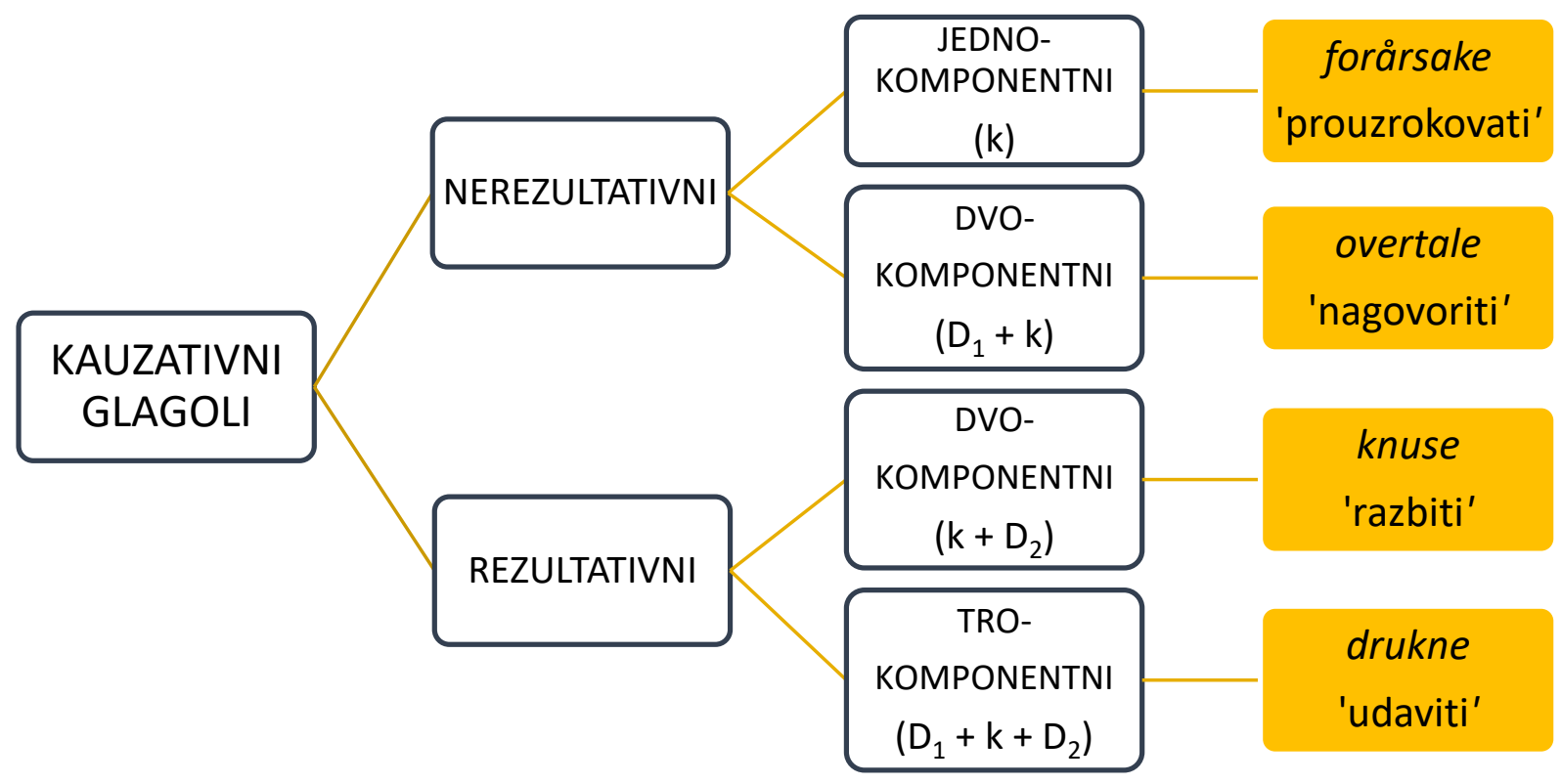

Dijagram 1. Semantička klasifikacija kauzativnih glagola prema Nedjalkovu i Siljnickom (Недялков \& Сильницкий 1969: 10) 
Osim toga, u literaturi se primenjuje i podela koju ćemo kao primarnu prihvatiti i u ovom radu, a to je podela na pomoćne i leksičke KG. Ova podela se može dopuniti podelom Nedjalkova i Siljnickog prema realizaciji komponenata.

\subsection{Pomoćni kauzativni glagoli}

Pomoćni KG su isključivo jednokomponentni glagoli i izražavaju semu kauzacije bez specifičnog leksičkog sadržaja, i čine predikat analitičkih kauzativnih konstrukcija ${ }^{3}$ (up. Bilandžija, 2013). Oni su ili desemantizovani (kao, na primer, glagol fă) ili predstavljaju kauzativno upotrebljene glagole veoma opšteg semantičkog sadržaja (kao, na primer, glagol gjøre). Pošto označavaju samo elementarnu semu kauzacije, oni su istovremeno i glagoli koji se koriste u parafraziranju semantičkog sadržaja drugih, multikomponentnih KG: legge (noe) $\rightarrow$ f̊ (noe) til \& ligge, starte (bilen) $\rightarrow$ fa (bilen) til å starte, minne (noen) $\rightarrow$ fa (noen) til à huske; glede (noen) $\rightarrow$ gjøre (noen) glad, minske (noe) $\rightarrow$ gjøre (noe) mindre, sentimentalisere (noe) $\rightarrow$ gjøre (noe) sentimental.

Termin pomoćni kauzativni glagol (šv. kausativt hjälpverb) etabliran je u švedskoj gramatičkoj tradiciji (Teleman et al. II: 536; IV: 296) ${ }^{4}$, i čini jednu od podgrupa pomoćnih glagola, uz temporalne, modalne, akcionalne i pasivske. Broj pomoćnih kauzativnih glagola je mali i njihov status pomoćnih glagola svedoči o visokom stepenu gramatikalizacije analitičkih kauzativnih konstrukcija u koje ulaze. Osim što iskazuje samo semu kauzacije, za razliku od jednokomponentnih leksičkih KG ( $v$. dole) njihovo značenje je u toj meri generalizovano da ne postavljaju nikakav zahtev kada su u pitanju semantičke karakteristike ili taksonomska klasa učesnika (čovek, životinja, događaj, okolnost, prirodna sila i sl.). Upravo zbog te nespecifičnosti kodiraju jednim oblikom ceo spektar tipova kauzacije, od direktne fizičke prisile, preko ubeđivanja, omogućavanja, pa sve do pukog prisustva koje dovodi do posledica reakcijskog tipa (up. Bilandžija, 2014).

\footnotetext{
3 U literaturi se nazivaju još і служебные каузативные глаголы (Недялков \& Сильницкий 1969: 9), auxiliary causative verbs (Shibatani 1976: 2), main (matrix) verb (Wolff 2003: 10; Stefanowitsch 2001: 1), auxiliary (Loewenthal 2003: 97) i causation verb (Stefanowitsch 2001: 35).

${ }^{4}$ Rawoens (2002: 324-325) smatra da glagoli fă, lăta, förmå, ha i komma imaju hjälpverbsliknande status (status koji nalikuje pomoćnom glagolu).
} 


\subsection{Leksički kauzativni glagoli}

Leksički kauzativni glagoli čine semantički raznovrsnu grupu. Svima im je zajedničko to što se, bez obzira na to koju od komponenata KS iskazuju, može smatrati da u kauzativne konstrukcije ulaze sa svojim punim leksičkim značenjem.

(1) Jednokomponentni KG označavaju samo komponentu kauzacije, i oni su, dakle, istovremeno i nerezultativni i neinstrumentalni, jer ne izražavaju bilo kakvu konkretnu aktivnost. Takvi su norveški glagoli bevirke, forårsake, foranledige, medføre, volde, gjøre, få til, beg̊̊, u značenju '(pro)uzrokovati', 'izazvati', 'dovesti (do)', 'činiti', 'počiniti'. Za razliku od pomoćnih KG, glagoli ove grupe imaju inherentno kauzativno značenje. Osim toga, Talmijeva istraživanja vezana za teorijski model Force Dynamics dovela su do toga da se u ovu grupu ne ubrajaju samo glagoli koji označavaju faktitivnost ('čistu' kauzaciju), već i oni koji označavaju omogućavanje ili sprečavanje. Granica između pomoćnih KG i jednokomponentnih leksičkih nije uvek oštra. Na primer, razlog što smo norveški glagol gjøre (sa osnovnim značenjem 'činiti') svrstali u pomoćne nije primarno njegova desemantizovanost, već prevashodno sposobnost da formira produktivne i sistemske, visoko gramatikalizovane kauzativne predikate, čiji su ekvivalenti u srpskom jeziku mahom jednoleksemski.

(2) Dvokomponentni KG se mogu razdvojiti u dve veće podgrupe, polazeći od toga da li se uz semu kauzacije kodira komponenta instrumentalnosti ili komponenta rezultativnosti.

(a) Instrumentalno-nerezultativni KG su oni koji izražavaju semu kauzacije i $D_{1}$. S obyirom na to da kauyativisti;ka literatura smatra da je način delovanja agensa u okvirima $D_{1}$ od manje važnosti od rezultata ka kom je radnja usmerena, ni ovakvih glagola nema mnogo. Takvi su najčešće tzv. koercivno-manipulativni glagoli (Givón 1975: 66) ili pseudokauzativni glagoli, odnosno glagoli koji pripadaju drugim semantičkim poljima, prvenstveno semantičkom polju glagola govorenja, a koji se u određenom kontekstu mogu interpretirati kauzativno. Takvi su, na primer, glagoli si 'reći', be 'zamoliti', beordre 'narediti', overtale 'nagovoriti', befale 'zapovediti'.

(b) Neinstrumentalno-rezultativni KG čine najobimniju grupu, jer ne specifikuju aktivnost agensa, ali kodiraju semu kauzacije i novonastalo stanje pacijensa. Glagol tipa knuse 'razbiti (u paramparčad)' specifikuje konkretnu promenu stanja pacijensa i 
rezultat radnje: pacijentivni učesnik zapravo prestaje da postoji u prvobitnom obliku, od njega ostaju komadići. Dovođenje u to stanje se moglo desiti na različite načine, i upravo ovaj nedostatak specifikacije $D_{1}$ omogućava da se na mestu subjekta kodira veći broj učesnika (Levin \& Rappaport Hovav 1995: 107).

Upravo činjenica da je fokus ovih KG na uzrokovanju kakvog rezultata, uzrok je tome što skandinavski autori veliki broj sintetičkih kauzativa nazivaju rezultativnim. Za sintetičke kauzative je karakteristična fuzija minimalno dva elementa KS u okviru jedne lekseme, ali kada se ovaj podtip KG nazove rezultativnim, isključuje se sema kauzacije, tj. poriče se uloga kakvog uzroka koji je doveo do pokretanja aktivnosti i nastanka datog rezultata, ma koliko $D_{1}$ bila nespecifikovana. Postavlja se pitanje zašto se termin rezultativan $u$ tom slučaju ne primenjuje na glagole spontane ili interne promene stanja, kao što su flatne ('ispraviti se'), dages ('svanuti') ili sprekke ('pući), kad oni označavaju spontane promene stanja, bez očiglednog eksternog uzroka, te je očiglednija komponenta rezultativnosti bez kauzacije.

U grupu neinstrumenalno-rezultativnih KG ubrajamo, na primer, glagole drepe 'ubiti', brekke 'slomiti', myke 'omekšati', bleke 'izblediti', bøye 'saviti', væte 'pokvasiti', åne 'otvoriti', fylle 'napuniti', skjerpe 'naoštriti', forbedre 'poboljšati', forverre 'pogoršati', skremme 'uplašiti', glede 'obradovati'.

(3) Trokomponentni $K G$ realizuju sve tri komponente $K S$, dakle, kauzaciju, $\mathrm{D}_{1} \mathrm{i}$ $D_{2}$, i mogu se nazvati instrumentalno-rezultativnim glagolima. Trokomponentni glagoli se mogu posmatrati često kao hiponimi kakvog manje specifičnog, tj. dvokomponentnog KG, sa kojim stoje u odnosu troponimije (Fellbaum 2002: 54). ${ }^{5}$ Ukoliko uporedimo glagol drepe ('ubiti') sa glagolima myrde, lynsje, skyte, henge, drukne ili kvele, uočavamo da jedino glagol drepe ne specifikuje način vršenja uzročnikove radnje, i broj mogućih učesnika na mestu subjekta je daleko veći nego kod njegovih hiponima (na primer, Per, bilen 'auto', tsunamien 'cunami', sykdommen 'bolest'). Ostali glagoli, uz semu uzrokovanja smrti drugog učesnika (rezultativnost), označavaju i konkretni način ispunjavanja date radnje, i mogu se smatrati hiponimima ili troponimima glagola drepe: myrde (s namerom), lynsje (veći broj učesnika, samovoljno), skyte (vatrenim oružjem), henge (vešanjem), drukne (u medijumu vode), kvele (sprečavanjem dotoka vazduha). Sličan odnos imamo, na primer, među glagolima očistiti i oprati: očistiti je dvokomponentni KG jer kodira samo rezultat

5 Troponimija je originalni termin Felbaumove za vrstu hiponimskog odnosa koji dominira strukturom glagolskog leksikona, i on označava načinski odnos ('vršiti radnju označenu hiperonimom X na određeni način'). 
(činiti/postići da nešto bude čisto), dok je oprati trokomponentni glagol, jer specifikuje način vršenja radnje (vodom i sapunom postići da nešto bude čisto).

Pitanje agentivnosti (stepena svesnosti, voljnosti, namere i kontrole) učesnika koji se kodira kao kauzator događaja, jedno je od ključnih pitanja semantike kauzativnosti, a u vezi sa podelom KG vezano je za pojmove instrumentalnosti i neinstrumentalnosti.

Komponenta agentivnosti je ono što može da utiče na licenciranje određenog subjekta od strane glagola. Iako se sa mnogim glagolima tipično javlja agens, među KG relativno mali broj uslovljava svesnog agensa na poziciji subjekta (Talmy, 2000: 509-524; Wolff, 2003: 15; Levin \& Rappaport Hovav, 2005: 27; Alexiadou, 2010: 179). Tek jedan manji broj glagolskih leksema ima strože zahteve supkategorizacije, tj. zahteva agensa sa komponentom voljnosti (i namere). To su one lekseme koje u svom semantičkom sadržaju imaju semu načina delovanja agensa kao, na primer, već pominjani dvokomponentni glagoli (podvrsta instrumentalno-nerezultativnih) čija su najreprezentativnija grupa verba dicendi, ili pak trokomponentni glagoli.

Glagol drepe, koji se može smatrati hiperonimom u semantičkom polju glagola ubijanja, dopušta prototipičnog svesnog agensa ali ga ne zahteva:

(3) a. Boka handler om en TV-stjerne som kidnapper småjenter og dreper dem. 'Knjiga govori o tv-zvezdi koja kidnapuje devojčice i ubija ih'

b. Hunden drepte en høne, og knakk vinger og rygg på to ender. 'Pas je ubio kokošku, a dvema patkama slomio krila i leđa'

c. Bilen som drepte syklistene kjørte over fartsgrensen. 'Automobil koji je ubio bicikliste, vozio je prekomernom brzinom'

d. Enkelte influensaer som har drept mange mennesker har stort sett drept de med godt immunforsvar. 'Pojedine vrste gripa koje su ubile veliki broj ljudi, ubijale su uglavnom one sa dobrim imunitetom'

e. Trafikken dreper mange piggsvin. 'Mnogo ježeva gine u saobraćaju', doslovno: 'Saobraćaj ubija mnogo ježeva'

f. Ulykken drepte alle passasjerene ombord. 'Svi putnici na brodu su poginuli u nesreći', doslovno: 'Nesreća je ubila sve putnike na brodu'

g. Livsstilen dreper norske menn. 'Norvežani umiru zbog životnog stila', doslovno: 'Stil života ubija Norvežane' 
Uočavamo da se na mestu subjekta glagola drepe pojavljuju i manje tipični agensi, kao što su životinje (hunden), mašine (bilen), okolnosti (trafikken, livsstilen) i događaji (ulykken).

Nasuprot ovom glagolu, trokomponentni glagoli iz datog semantičkog polja su daleko restriktivniji u pogledu licenciranja uloge na mestu subjekta. Za njih se može reći da su agentivni jer zahtevaju da na mestu subjekta bude prototipični agens:

Boka handler om en TV-stjerne som kidnapper småjenter og myrder dem. 'Knjiga govori o tv-zvezdi koja kidnapuje devojčice i ubija ih'

Agentivni KG, poput myrde, ne bi se mogao upotrebiti u primeru 3 (b-g) jer ima specifično značenje: u semantičkom sadržaju ovog glagola već je inkorporirana sema namere ${ }^{6}$, koja podrazumeva delovanje svesnog bića. Takvi su i glagoli sa inkorporiranom semom sredstva, koje može koristiti samo svesno biće: stikke ('izbosti'), knivstikke ('izbosti nožem'), dolke ('izbosti bodežom'), skyte ('upucati'). Aleksijadu (Alexiadou, 2010: 179) razlikuje glagole ovog tipa, koje naziva agentivnima, od glagola poput drepe, koji su samo glagoli eksternog uzroka.

Kod ovakvih glagola njih modifikacija purposivnim markerima dovodi do pleonastičnosti, a nepurposivnim do kontradikcije: *myrde (lynsje, henrette) noen med vilje 'ubiti (linčovati, pogubiti) nekoga namerno' ili *myrde (lynsje, henrette) noen ved et uhell 'ubiti (linčovati, pogubiti) nekoga nesrećnim slučajem'.

Glagol skyte se pak može svrstati i u dvo- i u trokomponentne KG. Donedavno se upotrebljavao samo kao trokomponentni glagol, čiji je rezultat nužno bio fatalan (up. na primer, nacističke plakate sa objavom Skutt blir den som... 'Streljani će biti svi koji...'). Danas se semantički sadržaj ovog glagola sužava prema engleskom obrascu, te je dominantna komponenta načinska (Han ble skutt og innlagt på sykehus 'Upucan je i smešten u bolnicu'), a predikacija rezultata (ako je ishod fatalan) se označavala glagolom drepe: De ble skutt (ned) og drept 'Pogođeni su i ubijeni'. Stoga se u novije doba paralelna upotreba oba glagola se ne smatra više pleonastičnom. Dakle, danas kao načinski i nerezultativan dozvoljava modifikaciju: Ektemannen skjøt henne ved et uhell, samo u značenju 'Muž ju je slučajno pogodio [harpunom]'.

\footnotetext{
${ }^{6} \mathrm{~S}$ ovim u vezi je i složena imenica seriemorder ('serijski ubica'), čije je jezgro izvedeno od glagola myrde, a ne od glagola drepe, iako postoji imenica drapsmann ('ubica'.
} 


\subsection{Kauzativni glagol i pripadnost semantičkom polju}

Komponenta kauzacije je jedina stalna komponenta, dok su drugi pokazatelji neregularni, pošto KG mogu pripadati najrazličitijim semantičkim poljima. Kao tri glavne grupe se mogu izdvojiti:

(a) glagoli transformativnog značenja, tj. glagoli koji označavaju promenu internih ili površinskih svojstava nekog entiteta, na primer, bleke 'izblediti', varme 'zagrejati', kjøle (ned) 'ohladiti', magnetisere 'namagnetisati', minske 'smanjiti', forstørre 'povećati', bukke 'saviti', vrenge 'iskriviti', rense 'očistiti', vaske 'oprati'. Učesnik koji se kodira na mestu objekta je pacijentivnog karaktera, a pošto je u potpunosti zahvaćen radnjom, u tradicionalnoj gramatici je poznat i pod nazivom aficirani objekat (no. retningsobjekt).

(b) glagoli kauzativno-egzistencijalnog značenja, koji označavaju nastanak ili prestajanje postojanja entiteta, na primer, bygge 'sagraditi', lage 'napraviti', skrive 'napisati', tegne 'nacrtati', bake 'ispeći'7; drepe 'ubiti', rive (ned) 'srušiti', spise opp 'pojesti'. Učesnik koji se kodira na mestu objekta poznat je u gramatici pod nazivom eficirani objekat (no. produktobjekt).

(c) glagoli transportativnog značenja označavaju premeštanje i smeštanje u prostoru: legge 'poleći', sette 'staviti / posesti', bevege 'pokrenuti', flytte 'premestiti', røre 'pomeriti', bære 'preneti', kjøre i frakte 'prevesti', strø (omkring) 'razbacati', fjerne 'udaljiti/odstraniti'.

Osim ove podele, moguće je podeliti KG na osnovu toga da li označavaju kauzaciju stanja ili procesa (tipično transformativni i kauzativno-egzistencijalni) ili kauzaciju aktivnosti (neki transportativni i kauzativno-ingestivni - hraniti, pojiti, napasati, dojiti; tzv. dvopersonalni sintetički kauzativi). Ova podela korespondira sa onim što je još Mekoli (McCawley) sedamdesetih godina XX veka primetio u vezi sa različitom prirodom odnosa između uzroka i efekta, te uzroka i rezultata, pri čemu prvi odnos karakteriše to da su i $D_{1}$ i $D_{2}$ eventivne prirode, dok je za drugi odnos

\footnotetext{
7 Ponekad se glagol može svrstati u dve grupe: tako glagol bake može biti transformativan kada kolocira sa imenicom potet 'krompir' (njegovo stanje se menja iz sirovog u pečeno), a može se smatrati i kauzativnoegzistencijalnim kada na taj način entitet nastaje (bake kake 'ispeći kola').
} 
karakteristično to da je $D_{1}$ eventivne prirode, dok je $D_{2}$ nužno stanje (prema Farber 1976: 61).

\section{Zaključne napomene}

U ovom radu smo izložili predlog klasifikacije kauzativnih glagola u savremenom norveškom jeziku u skladu sa nekoliko tradicionalnih pristupa u obimnoj kauzativističkoj literaturi. U njoj se pažnja već dugo posvećuje kauzativima, tj. glagolima koji imaju produktivnu kauzativnu morfologiju, i onim jezicima koji u svom sistemu imaju produktivan proces kauzativizacije. U norveškom jeziku, koji ima samo ostatke kauzativizacije (neproduktivni morfološki kauzativ), srž kategorije KG čine zapravo prelazni glagoli sa kauzativnim značenjem (ili čak samo povremenom kauzativnom interpretacijom).

To su takozvani leksički kauzativni glagoli sa očuvanom semantičkim sadržajem, dok smo nasuprot njima izdvojili i jednu manju supklasu pomoćnih kauzativnih glagola, čiji je semantički sadržaj depleciran, odn. istrošen. Oni iskazuju samo semu kauzacije, bez ekspliciranja komponente načina na koji je događaj uzrokovan ili tipa rezultata koji je nastao, a osim toga produktivnog obrazuju analitičke kauzativne konstrukcije (visok stepen gramatikalizacije konstrukcije). Bliski njima su jednokomponentni leksički kauzativni glagoli (izražavaju samo semu kauzacije), ali za razliku od pomoćnih, oni i dalje čuvaju punoznačnost svoje semantičke strukture (visok stepen leksikalizacije konstrukcija u koje ulaze).

\section{Literatura}

Alexiadou, A. (2010). On the Morphosyntax of (Anti)Causative Verbs. U M. Rappaport Hovav, E. Doron, \& I. Sichel (ur.), Lexical Semantics, Syntax and Event Structure (s. 177-203). Oxford: Oxford University Press.

Bilandžija, S. (2013). Supkategorizacija verbalnih kauzativnih konstrukcija u norveškom jeziku: analitički kauzativ. Komunikacija i kultura online, 4: 1-12.

Bilandžija, S. (2014). Semantika kauzativnih konstrukcija u norveškom i srpskom jeziku [neobjavljena doktorska disertacija]. Beograd: Filološki fakultet.

Bilandžija, S. (2015). Benefaktivni kauzativ i norveški FÅ-pasiv. Anali Filološkog fakulteta XXVII (2): 351-367.

Bilandžija, S. (2016). Prilog supkategorizaciji kauzativnih konstrukcija: morfološki kauzativ u savremenom norveškom jeziku. U J. Kostić-Tomović et al. (ur.), U 
carstvu reči - jezici i kulture. Zbornik u čast prof. dr Jovanu Đukanoviću povodom 85. rođendana (s. 188-200). Beograd: Filološki fakultet u Beogradu/ FOKUS Forum za interkulturnu komunikaciju.

Bilandžija, S. (2018). Neglagolske kauzativne konstrukcije u savremenom norveškom jeziku: predlog supkategorizacije. U Z. Kašić (ur.), O jeziku sa raznih aspekata. Zbornik u čast prof. dr Vesni Berić-Đukić (s. 195-207). Novi Sad/Beograd: Društvo za primenjenu lingvistiku Srbije; Filozofski fakultet Univerziteta u Novom Sadu; Filološki fakultet Univerziteta u Beogradu.

Croft, W. (1998). The Structure of Events and the Structure of Language. U M. Tomasello (ur.), The New Psychology of Language:Cognitive and Functional Approaches to Language Structure, Vol. 1 (s. 67-92). New Jersey/London: Lawrence Erlbaum Associates.

Croft, W. (1991). Syntactic Categories and Grammatical Relations. The Cognitive Organization of Information. Chicago/London: The University of Chicago Press.

Faarlund, J. T., Lie S. \& Vannebo, K. I. (1997). Norsk referansegrammatikk. Oslo: Universitetsforlaget.

Farber, J. (1976). The Semantics of Causative Verbs [doktorska disertacija]. New Jersey: Rutgers University.

Fellbaum, Christiane (2002). Autotroponymy. U Y. Ravin \& C. Leacock (ur.), Polysemy. Theoretical and Computational Approaches (s. 52-67). Oxford: Oxford University Press.

Givón, T. (1975). Cause and control: on the semantics of interpersonal manipulation. U J. P. Kimball (ur.), Syntax and Semantics 4 (s. 59-89). New York: Academic Press.

Golden, A., MacDonald, K. \& Ryen, E. (32008). Norsk som fremmedspråk. Grammatikk. Oslo: Universitetsforlaget.

Hamon, S., Amy, M., \& Anscombre, J-C. (2006). Présentation. U S. Hamon \& M. Amy (ur.), La cause: approche pluridisciplinaire (s. 11-17). Linx 54, Revue des linguistes de l'Université Paris Ouest Nanterre La Défense.

Хазагеров, Т.Г. (1998). Каузативность: статус и эволюция средств выражения в русском языке. Филологический вестник Ростовского государственного университета 2: 23-28.

Kelstrup, S. (2001). Introduktion til typologi. København: Institut for Almen og Anvendt Sprogvidenskab, Københavns Universitet. 
Kulikov, L. I. (2001). Causatives. U M. Haspelmath et al. (ur.), Language Typology and Language Universals, Vol. 2 (s. 886-898). Berlin, New York: Walter de Gruyter.

Levin, B. \& Rappaport Hovav, M. (1995). Unaccusativity. At the Syntax-Lexical Semantics Interface. Cambridge, London: The MIT Press.

Levin, B. \& Rappaport Hovav, M. (2005). Argument Realization. Cambridge: Cambridge University Press.

Loewenthal, J. (2003). Meaning and use of causeeless causative constructions with laten in Dutch. U A. Verhagen \& J. van de Weijer (ur.), Usage-Based Approaches to Dutch. Lexicon, grammar, discourse (s. 97-129). Utrecht: LOT.

Недялков, В.П. \& Сильницкий, Г.Г. (1969а). Типология каузативных конструкций. У А.А.Холодович (ред.), Типология каузативных конструкций. Морфологический каузатив (с. 5-19). Ленинград: Наука

Rawoens, G. (2007). Kausativa verbkonstruktioner i svenskan och nederländskan. En korpusbaserad syntaktisk-semantisk undersökning [doktorska disertacija]. Gent: Universiteit Gent.

Shibatani, M. (1976). The grammar of causative constructions: a conspectus. U M. Shibatani (ur.), Syntax and Semantics 6 (s. 1-40). New York: Academic Press.

Shibatani, M. (2001). Some basic issues in the grammar of causation. U M. Shibatani (ur.), The Grammar of Causation and Interpersonal Manipulation (s. 1-22). Amsterdam, Philadelphia: John Benjamins Publishing Company.

Shibatani, M. \& Pardeshi, P. (2001). The Causative Continuum. U M. Shibatani (ur.), The Grammar of Causation and Interpersonal Manipulation (s. 85-126). Amsterdam, Philadelphia: John Benjamins Publishing Company.

Stefanowitsch, A. (2001). Constructing causation: A Construction Grammar Approach to Analytic Causatives [doktorska disertacija]. Houston: Rice University.

Talmy, L. (2000). Toward a cognitive semantics. Vol. I: Concept Structuring Systems. Cambridge MA, London. MIT Press.

Teleman, U., Hellberg, S. \& Andersson, E. (1999). Svenska Akademiens grammatik IIV. Stockholm: Norstedts.

Vázquez Rozas, V. (2007). A usage-based approach to prototypical transitivity. U N. Delbecque \& B. Cornillie (ur.), On Interpreting Construction Schemas: From Action and Motion to Transitivity and Causality (s. 17-37). Berlin/New York: Mouton de Gruyter.

Vinje, F-E. (71990). Kompendium i grammatisk analyse. Oslo: Universitetsforlaget. 
Wolff, P. (2003). Direct causation in the linguistic coding and individuation of causal events. Cognition 88: 1-48.

\section{Summary}

\section{ON THE NOTION AND DELINEATION OF THE TERM 'CAUSATIVE VERB' IN CONTEMPORARY NORWEGIAN}

This paper is concerned with the definition and delineation of the so-called causative verbs in contemporary Norwegian. Norwegian and Scandinavian grammars have somewhat diverse notions of the causative verbs, for the most part too narrow, often contrasting them with resultative and factitive verbs. Decades of typological, semantic, and syntactic studies within research on causation show that all these verbs can be classified as causative in Norwegian, an Indo-European language with no productive morphological causatives. The crux of causative verbs lies thus in transitive verbs with causative meanings (or sometimes rather causative interpretation).

The author first distinguishes auxiliary causative verbs from the lexical causative verbs. The former, such as $f a$ (til) and gjøre, show a high degree of semantic depletion, expressing only the causation component and being the pivotal point of highly productive and grammaticalized analytic causative constructions. These constructions are therefore semantically unmarked, with different types of agents and agent-like participants surfacing as their subjects, and the constructions express high degree of 'unspecified' indirect causation.

Lexical causative verbs can be classified into (1) one-component lexical causatives, expressing only the notion of causing an event, while retaining the remainder of the verbs lexical meaning (such as bevirke, forårsake, foranledige or medføre), (2) two-component lexical causatives, expressing the causation component together with either the feature of the causing subevent (many pseudo-causative verbs, such as verba dicendi represented by e.g. be, beordre, overtale, befale) or the feature of the caused subevent (traditional resultatives, such as knuse, brekke, myke, bleke, bøye, væte, åpne, fylle, skjerpe, forbedre, forverre, skremme or glede), and finally (3) three-component lexical causatives, expressing the notion of causation together with both the feature of the causing and the caused subevent (myrde, lynsje, henrette, vaske). The paper also discusses in some detail the notion of the so-called instrumentality in connection with instrumental two-component causatives and three-component causatives, in relation to the notions of agentivity and the causatives licensing specific causers as their subjects.

We then go on to establish three main semantic fields that Norwegian causative verbs are a part of.

Key words: causativity, causative verb, causative, causative situation, causative construction, Norwegian. 